\title{
Hydrazone-Containing Triblock Copolymeric Micelles for pH-Controlled Drug Delivery
}

\author{
Peilan Qi, Xiaohe Wu, Lei Liu*, Huimin Yu and Shiyong Song* \\ Institute of Pharmacy, Pharmaceutical College of Henan University, Kaifeng, China
}

In this study, the structure-activity relationship of amphiphilic block copolymer micelles as nanosized drug delivery system was revealed. Firstly, a biodegradable triblock polymers PEG-DiHyd-PLA containing hydrazone bond was synthesized through the ring-opening polymerization. In this method, PEG-DiHyd-Phenol was used as the initiator and L-lactide as the monomer. Then, the polymeric micelles were formed and used as nano-drug carriers with $\mathrm{pH}$ sensitivity. The structure and composition of the polymer were characterized by infrared (IR), nuclear magnetic resonance ( $\left.{ }^{1} \mathrm{H}-\mathrm{NMR}\right)$, and gel permeation

OPEN ACCESS

Edited by:

Qingxin $\mathrm{Mu}$,

University of Washington,

United States

Reviewed by:

Liwen Li,

University of Pittsburgh Cancer Institute, United States

Lei Xing,

China Pharmaceutical University, China

${ }^{*}$ Correspondence:

Lei Liu

liulei@henu.edu.cn

Shiyong Song

pharmsong@outlook.com

Specialty section:

This article was submitted to Cancer Molecular Targets and

Therapeutics,

a section of the journal

Frontiers in Pharmacology

Received: 30 October 2017

Accepted: 05 January 2018

Published: 23 January 2018

Citation:

Qi P, WU X, Liu L, Yu H and Song S

(2018) Hydrazone-Containing Triblock

Copolymeric Micelles for pH-Controlled Drug Delivery.

Front. Pharmacol. 9:12.

doi: 10.3389/fphar.2018.00012 chromatography (GPC), we characterized the self-assembling process of the triblock polymers and the $\mathrm{pH}$ sensitivity of the micelles by the means of transmission electron microscopy (TEM), dynamic light scattering method (DLS). Doxorubicin (DOX) acts as the model drug, and we researched the capacities of drug loading and release in vitro of the micelles. MTT experiments showed that the blank micelles of PEG-DiHyd-PLA were not cytotoxic to tumor cells (HepG-2, MCF-7) and normal cell (L-02 cells), but the DOX loaded ones displayed more toxicity than the ones without hydrazone, which was consistent to the further confocal laser scanning microscopy and flow cytometry study.

Keywords: triblock copolymer, pH-sensitive, cytotoxicity, micelles, tumor targeting

\section{INTRODUCTION}

In the past two decades, a large number of nanoparticulate drug delivery systems have been extensively explored as in cancer treatment. Some formulations in the form of liposome, polymer-drug conjugates, and micelle particulate have found their applications in clinics and even more are advanced to the stage of clinical trials. Recently, more sophisticated nano-system have been developed to increase the therapeutic efficacy of cancer by controlling of the drug release temporally or spatially. Stimuli-response functionality is becoming increasingly important due to applications in biotechnology and the crafting of smart materials. Stimulus (Xing et al., 2011), such as pH (Hrubý et al., 2005; Huang et al., 2015; Mei et al., 2016), temperature (Seo et al., 2015), reductant (Deng et al., 2015), and so on (Cheng et al., 2015), were applied to modulate the release profile of the therapeutic agents. Polymeric micelles that possess stimuli-responsive properties have been demonstrated their great potentials in maximizing the therapeutic efficacy by prolonging circulation life of drug, and minimizing side effects (Makino et al., 2015).

It was reported that it is more acidic around tumor than in blood and normal tissue (Webb et al., 2011). The inherent characteristic of tumor tissue makes $\mathrm{pH}$-sensitive drug delivery systems more suitable for cancer chemotherapy. Furthermore, after endocytosis of the $\mathrm{pH}$-sensitive micelles, an accelerated release of the payload occurs in endosomes and lysosomes, which have the low-pH of pH 5.5-6.0 and pH 4.5-5.0, respectively (Zheng et al., 2013). 
A pH sensitive drug delivery system can be formed chemically or physically. Polymer-drug conjugate is one of the $\mathrm{pH}$ responsive drug delivery systems that bearing with acid sensitive linkages between therapeutic molecule and polymer. Ulbrich (Hrubý et al., 2005; Ulbrich and Šubr, 2010) and Kataoka (Bae et al., 2003) conjugated block copolymers with doxorubicin (DOX) with an acid labile hydrazone containing linkage. The conjugates can form micelles and a boost release of DOX were found in an acidic environment upon the cleavage of hydrazone bonds. Hu et al. (2010) prepared biodegradable polymeric micelles with DOX conjugated block copolymer via hydrazone and carbamate linkage for DOX and the hydrazone ones have higher $\mathrm{pH}$-sensitivity than the others. While, the frequently used hydrazone bond can only be formed between the DOX and hydrazine motif containing polymer. Anticancer drugs, such as paclitaxel, camptothecin and gemcitabine, are not appropriate for the linkage of hydrazone.

Physical entrapment of hydrophobic anticancer drugs in the core of a $\mathrm{pH}$-responsive polymeric micelles is another way of forming a $\mathrm{pH}$ responsive system. In this case, $\mathrm{pH}$ sensitive parts are fixed on the body of carrier, on the side chain or backbone of the copolymer which forms the micelle, where sufficient structural changes are initiated in the low $\mathrm{pH}$ environment, triggering a boost release of drug simultaneously. Ding et al. (2009) connected poly(ethylene glycol) with stearic acid via a Schiff base bond linkage to form a $\mathrm{pH}$-sensitive amphiphilic molecule mPEG-b-C18. The cleavage of the Schiff base bond under acidic condition resulted in disassociation of micelle and accelerated drug release. It is obvious that this kind of $\mathrm{pH}$ sensitive linkage is applicable for DOX but not limited to. The chemistry of $\mathrm{pH}$-sensitive bond determines the performance of the drug delivery systems. There should be a perfect sensitivity that be able to hydrolyze quickly in acidic environments and stay unchanged in others. Acid labile linkages such as hydrazone (Bae et al., 2003; Hrubý et al., 2005; Hu et al., 2010; Ulbrich and Šubr, 2010), acetal (Gillies et al., 2004; Lu et al., 2010), orthoester (Tang et al., 2011; Cheng et al., 2012), citraconic amide (Cao et al., 2014), and Schiff base bonds (Ding et al., 2009) were reported. Among them, hydrazones were studied extensively for the easy preparations, moderate stability and favorable sensitivity.

In addition, the nature of micelle-forming amphiphilic copolymer should be also considered with respect to the biocompatibility, biodegradability, and capacity of drug loading. Usually biodegradable polymers such as polyester, poly (amino acid), and poly (anhydride) are core-forming materials and polyethylene glycols (PEG) (McPherson et al., 1998; Vonarbourg et al., 2006) form hydrophilic shell of micelles. The polyesters are preferred for their good biocompatibility and degradability (Witschi and Doelker, 1998). Poly (lactic acid) is widely used in drug delivery systems for its moderate degradation rate (Sinha et al., 2004).

In our previous studies, hydrazone containing di-block copolymers were used to form $\mathrm{pH}$-sensitive carriers (Qi et al., 2017). Furthermore, with the discovery of more and more biocompatible polymer materials and atom transfer radical polymerization (ATRP) is becoming more and more mature (Cavallaro et al., 2014; Park et al., 2014; Ran et al., 2014; Visnevskij et al., 2014), triblock polymer has become favorable. Triblock polymers also can be used as drug carriers that aremore stable and controllable (Han et al., 2016). In this work, it was started with rational designing of PEG-based marcro-initiators with hydrazone bond imbedded, then hydrophobic polyester segment was incorporated by ring-opening polymerization. Micelles from the amphiphilic block polymer are both biodegradable and $\mathrm{pH}$ sensitive, for the controlled release of DOX.

\section{MATERIALS AND METHODS}

\section{Materials}

Polyethylene glycol (PEG; Mn = 6,000) was purchased from Sigma-Aldrich (St. Louis, MO, USA) and dried in a vacuum oven at $70^{\circ} \mathrm{C}$ before use. L-Lactide (99.5\%, Jinan Daigang Biomaterials Co. Ltd., Jinan, China), stannous octanoate [Sn(Oct) $)_{2}$, 95\%, Sigma-Aldrich, St. Louis, MO, USA], 4carboxybenzaldehyde (98\%, Shanghai Darui, Shanghai, China), N,N'-dicyclohexylcarbodiimide (DCC, 98\% Shanghai Darui, Shanghai, China), 4-dimethylaminopyridine (DMAP, 98\% Shanghai Darui, Shanghai, China), methyl 4-hydroxybenzoate (98\%, Shanghai Darui, Shanghai, China), and hydrazine hydrate aqueous solution (80\%,Tianjin Kemiou, Tianjin, China) were used as received. Doxorubicin hydrochloride (Dalan Meilun Biotech., Dalian, China) was stirred with TEA (3 equiv.) in DMSO overnight before the solvent was evaporated using a rotary evaporator to get doxorubicin, i.e., DOX. All organic solvents were analytical reagents and used as received, except that toluene was dried by the sodium method to get anhydrous toluene.

\section{Preparation of Tri-block Copolymer PEG-DiHyd-PLA Synthesis of Dialdehyde Polyethylene Glycol (CHO-PEG-CHO)}

CHO-PEG-CHO was prepared according to the reported procedure with some modifications (Ding et al., 2009). Firstly, PEG $(8 \mathrm{~g})$ in dichloromethane (DCM) $(100 \mathrm{~mL})$ reacted with 4carboxybenzaldehyde in the presence of DCC ( $3 \mathrm{~g})$ and DMAP $(0.5 \mathrm{~g})$ for $72 \mathrm{~h}$ in the oil bath of $40^{\circ} \mathrm{C}$. Secondly, the solution was filtered and remove the white precipitate impurities of generated. After that, the filtrate was poured into a large amount of ether for precipitation and the solid was recrystallized three times with isopropyl alcohol. Finally, the product is dried in a vacuum drying chamber at $40^{\circ} \mathrm{C}$ to obtain a white powder solid. CHO-PEG-CHO white powder was obtained with a yield of $92.4 \%$. Nuclear magnetic resonance $\left({ }^{1} \mathrm{H}-\mathrm{NMR}\right)(400 \mathrm{MHz}$, $\mathrm{CDCl}_{3}$ ): $\delta 10.12$ (Ar-CHO), $\delta 8.21, \delta 7.97$ (aromatic protons), $\delta 3.65$ $\left(-\mathrm{OCH}_{2} \mathrm{CH}_{2} \mathrm{O}-\right)$, 84.52 (-COOCCHO-).

\section{Synthesis of (PEG-DiHyd-Phenol) Containing a Hydrazone Bond Initiator}

Fristly, 4-hydroxybenzoylhydrazine was synthesized according to the previous method (Zheng et al., 2007). Then, 4Hydroxybenzoichydrazine $(0.3 \mathrm{~g})$ reacted with $\mathrm{CHO}-\mathrm{PEG}-\mathrm{CHO}$ $(4 \mathrm{~g})$ in $30 \mathrm{ml}$ methanol and $10 \mathrm{ml} \mathrm{N}, \mathrm{N}$-methyl formamide (DMF) at $68^{\circ} \mathrm{C}$ for $18 \mathrm{~h}$. PEG-DiHyd-Phenol was also obtained 
by precipitation in ethylether, and yellow powder was obtained. ${ }^{1} \mathrm{H}-\mathrm{NMR}\left(400 \mathrm{MHz}, \mathrm{CDCl}_{3}\right)$ : $\delta 8.41(\mathrm{Ar}-\mathrm{CH}=\mathrm{N}), \delta 10.58$ (Ar$\mathrm{OH}), \delta 3.60\left(-\mathrm{OCH}_{2} \mathrm{CH}_{2} \mathrm{O}-\right)$.

\section{Synthesis of Triblock Copolymer PEG-DiHyd-PLA by Ring-Opening Polymerization}

PEG-DiHyd-Phenol and L-lactide reacted in anhydrous toluene in the presence of stannous octanoate $(100 \mu \mathrm{L})$. PEG-DiHydPLA with different molecular weights were synthesized by varying the ratio between PEG-DiHyd-Phenol and L-lactide. The reactions were conducted at $110^{\circ} \mathrm{C}$ under the protection of nitrogen gas for $24 \mathrm{~h}$. The copolymer was precipitated three times with cold ethyl ether. It was dried at $45^{\circ} \mathrm{C}$ in vacuum. PEG-DiHyd-PLA were obtained with a yield of $72 \% .{ }^{1} \mathrm{H}-\mathrm{NMR}$ $\left(400 \mathrm{MHz}, \mathrm{CDCl}_{3}\right): \delta 3.64\left(-\mathrm{OCH}_{2} \mathrm{CH}_{2} \mathrm{O}-\right) ; \delta 8.42(\mathrm{Ar}-\mathrm{CH}=\mathrm{N})$; $\delta 5.21$ [protons on poly(L-lactic acid) part]; and $\delta 8.09, \delta 7.92$, $\delta 7.84$, and $\delta 6.98$ (aromatic protons). Meanwhile, PLA-PEG-PLA copolymers without hydrazone linkage were also prepared as $\mathrm{pH}$ non-responsive counterpart using PEG as the initiator.

\section{Characterization}

An AVATAR360 (Nicolet, USA) and an AVANCE 400 spectrometer (Brucker, Switzerland) were used to determine the chemical structure of the polymers. A Damn Eos (Wyatt, USA) gel permeation chromatograph (GPC) instrument equipped with Phenogel 10E6A column and an OPTILAB rEX refractive-index detector was used to determine the molecular weight and polydispersity. Tetrahydrofuran (THF) was used as the eluent at a flow rate of $1.0 \mathrm{~mL} / \mathrm{min}$ at $30^{\circ} \mathrm{C}$ and polystyrene standards for the calibration. A Zetasizer Nano-ZS90 (Malvern Instruments, UK) and Transmission electron microscopy (JEM-100CX II TEM) were employed to determine the size and the morphology of the micelles.

\section{Formation of the pH-Sensitive Micelles}

PLA-PEG-PLA or PEG-DiHyd-PLA $(30 \mathrm{mg}$ ) dissolved in THF $2 \mathrm{~mL}$ was added into $40 \mathrm{~mL}$ pure water by dropwise. The mixture was stirred for $36 \mathrm{~h}$ at room temperature. The sizes evolution in different solutions of the micelles were measured to determine the $\mathrm{pH}$ sensitivity. Ten milliliters freshly prepared micelle dispersions was adjusted to $\mathrm{pH} 5.0$ or $\mathrm{pH} 4.0$. The sizes were measured on DLS after $24 \mathrm{~h}$ incubation at $37^{\circ} \mathrm{C}$ with shaking. CMC was determined using pyrene as a fluorescence probe (Xu et al., 2016).

\section{Drug Loading and Release}

DOX was loaded into the micelles by solvent evaporation method. Typically, copolymers (25 mg) and DOX (2 mg) were dissolved in $1 \mathrm{~mL}$ acetone. The solution was added dropwise into $30 \mathrm{~mL}$ pure water stirring. Then, the micellar solution was dialyzed against water for $36 \mathrm{~h}$. After filtered through a $0.22 \mu \mathrm{m}$ syringe filter to remove undissolved DOX, DOX-loaded micelle dispersion was freeze-dried. The drug loading content (DLC was determined by the measurement of fluorescence of DOX (excitation wavelength at $481 \mathrm{~nm}$ and emission wavelength at $558 \mathrm{~nm})$. DLC was calculated by the formula below:

$$
\begin{aligned}
\text { DLC }(\text { wt } \%)= & \text { (weight of loaded drug/weight of drug loaded } \\
& \text { micelles }) \times 100 \%
\end{aligned}
$$

The in vitro release experiments of DOX were conducted at $37^{\circ} \mathrm{C}$. Dialysis bag (molecular weight cut-off: 8,000-14,000) filled with $3 \mathrm{~mL}$ micellar solution was sealed and immersed in $40 \mathrm{~mL}$ buffers solution. Three buffer solutions were used: acetate buffer $(0.01 \mathrm{M}$, $\mathrm{pH}=4)$, acetate buffer $(0.01 \mathrm{M}, \mathrm{pH}=5)$, and PBS $(0.01 \mathrm{M}$, $\mathrm{pH}=7.4)$. At desired time intervals, $4 \mathrm{~mL}$ of solution outside was taken out for fluorescence measurement. Meanwhile, $4 \mathrm{~mL}$ fresh medium was replenished. Cumulative released DOX was calculated according to following formula:

$$
E_{r}=\frac{V_{e} \sum_{1}^{n-1} C_{i}+V_{0} C_{n}}{m_{\text {drug }}}
$$

In this equation, $E_{r}$ means cumulative release of $\operatorname{DOX}(\%) ; V_{e}$ means volume to be taken very time $(\mathrm{mL}) ; V_{0}$, the volume of medium (mL); $C_{i}$, concentration when certain volume to be taken $(\mu \mathrm{g} / \mathrm{mL}) ; m_{d r u g}$, total mass of DOX contained in the release system $(\mu \mathrm{g}) ; n$, sampling times.

\section{In Vitro Toxicity Evaluation}

MTT assay was applied to evaluate the cytotoxicity of the blank micelles, DOX-loaded micelles, using HepG-2, MCF-7, and normal L-02 cells (from the Shanghai cell bank of the Chinese Academy of Sciences, Shanghai, China). Cells were seeded and incubated for $24 \mathrm{~h}\left(37^{\circ} \mathrm{C}, 5 \% \mathrm{CO}_{2}\right)$ on a 96 -well plate. The cell density is $5 \times 10^{3}$ cells per well in $100 \mu \mathrm{L}$ of 1640 medium (containing $10 \% \mathrm{FBS}$ ). $24 \mathrm{~h}$ later, the medium in each well was removed and $100 \mu \mathrm{L}$ DOX-loaded micelles or free DOX solution were added into the wells. Each concentration has four replicates. Each sample was performed in quintuplicate. After incubation for $48 \mathrm{~h}$, and the viability of cells was measured using the methylthiazoletetrazolium method. Cell viability (\%) was calculated by the following equation (Ahmad et al., 2014):

$$
\text { Cell Viability }(\%)=\left(\mathrm{A}_{\text {sample }} / \mathrm{A}_{\text {control }}\right) \times 100
$$

where $\mathrm{A}_{\text {sample }}$ and $\mathrm{A}_{\text {control }}$ is absorbance of the sample well and control well, respectively. Data are presented as average $\mathrm{SD} \pm$ $(n=3)$.

\section{Confocal Laser Scanning Microscopy}

HepG-2 cells were seeded on the cover slips in culture dish with a density of $8 \times 10^{4}$ cell using RPMI-1640 medium supplemented with $10 \%$ FBS. $24 \mathrm{~h}$ later, free DOX, DOX-loaded PEG-DiHydPLA, and PLA-PEG-PLA micelles were added into the wells at the same DOX concentration of $10 \mu \mathrm{g} / \mathrm{mL}$. After being incubated at $37^{\circ} \mathrm{C}$ for 3 and $12 \mathrm{~h}$, the cells were washed with PBS and fixed with PBS containing 4\% formaldehyde for $15 \mathrm{~min}$ at room temperature. The cell nuclei were stained with $4^{\prime}, 6$-diamidino2-phenylindole (DAPI) for $15 \mathrm{~min}$. The fluorescence signals of DOX and DAPI staining were investigated and imaged by the confocal laser scanning microscopy system (CLSM). 


\section{Flow Cytometry Measurements}

DOX-loaded micelles and free DOX uptake HepG-2 cells was assessed using the flow cytometry cell analyzer. HepG-2 cells were seeded in culture dish $\left(5 \times 10^{5}\right.$ cells $)$ in 1640 media and incubated for $24 \mathrm{~h}$ at $37^{\circ} \mathrm{C}$. Then, HepG-2 Cells were treated with $1.5 \mathrm{~mL}$ of fresh cell culture medium and containing free DOX and DOX-loaded nanoparticles (equivalent concentration of DOX was $10 \mu \mathrm{g} / \mathrm{mL}$ ) were added. After $48 \mathrm{~h}$ of incubation, the drug containing media was collected, and cells were trypsinized (without EDTA), centrifuged, washed with Binding Buffer (1X) for two times. Then collect the cells, and stained with Annexin V-FITC and propidium iodide (PI) for $20 \mathrm{~min}$ following the operating instructions (In the dark environment). Finally, the sample was tested by flow cytometry within $1 \mathrm{~h}$.

\section{Statistical Analysis}

Origin 8.5 and GraphPad Prism 5.0 Software were used for the statistical analysis Differences were considered statistically significant at $P<0.05$, via one-way ANOVA and Student's $t$-test.

\section{RESULTS AND DISCUSSION}

\section{Synthesis of pH Sensitive Tri-block Copolymers}

The triblock polymer with hydrazone on the backbone was prepared by a direct polymerization method (Figure 1). A hydrazone containing macro-initiator was synthesized first which followed by a ring opening polymerization. The synthesis is illustrated in Figure 2. CHO-PEG-CHO was firstly obtained by conjugation of PEG with 4-carboxybenzaldehyde. And 4-hydroxybenzoichydrazide was synthesized from methyl 4hydroxybenzoate. The reaction between $\mathrm{CHO}-\mathrm{PEG}-\mathrm{CHO}$ and 4-hydroxybenzoichydrazide gave a molecule which embedded with hydrazone bond and terminal hydroxyl group. It could initiate ring-opening polymerization of lactide, to produce the copolymer PEG-DiHyd-PLA. The ${ }^{1} \mathrm{H}-\mathrm{NMR}$ spectra of CHOPEG-CHO (Figure 3A) show signals characteristic of $\delta 10.12$ (Ar$\mathrm{CHO}), \delta 8.21, \delta 7.97$ (aromatic protons), $\delta 3.65\left(-\mathrm{OCH}_{2} \mathrm{CH}_{2} \mathrm{O}-\right)$, and $\delta 4.52$ (-COOCCHO-). Through the above analysis, we can confirm the success of the synthesis of CHO-PEG-CHO. ${ }^{1} \mathrm{H}$ NMR showed that the macroinitiator PEG-DiHyd-Phenol was successfully synthesized, as indicated by the signal at $\delta 8.41$, which was assigned to hydrazone protons $(\mathrm{Ar}-\mathrm{CH}=\mathrm{N})$ (Figure 3B). In the spectra of PEG-DiHyd-PLA (Figure 3C), characteristic signals of PEG ( $\delta 3.64)$, and poly (L-lactic acid) part ( $\delta 5.21$, $\delta 8.09, \delta 7.92, \delta 7.84$, and $\delta 6.98)$ appeared. The characteristic signals of hydrazone bond ( $\delta 8.42)$ were found to confirm the successful synthesis of PEG-DiHyd-PLA. PLA-PEG-PLA without $\mathrm{pH}$-sensitive linkage was also synthesized.

Molecular weights of synthesized polymers are listed in Table 1. PEG-DiHyd-PLA-15K, PEG-DiHyd-PLA-18K, and PEG-DiHyd-PLA-20K are three copolymers with different molecule weights by designation, corresponding to the feed ratios $1: 127,1: 169$, and 1:197 between initiator and monomer, respectively. They have the same hydrophilic block PEG $(\mathrm{Mn}=5,267 \mathrm{~g} / \mathrm{mol})$ and different hydrophobic blocks in different molecular weights. The molecular weights were

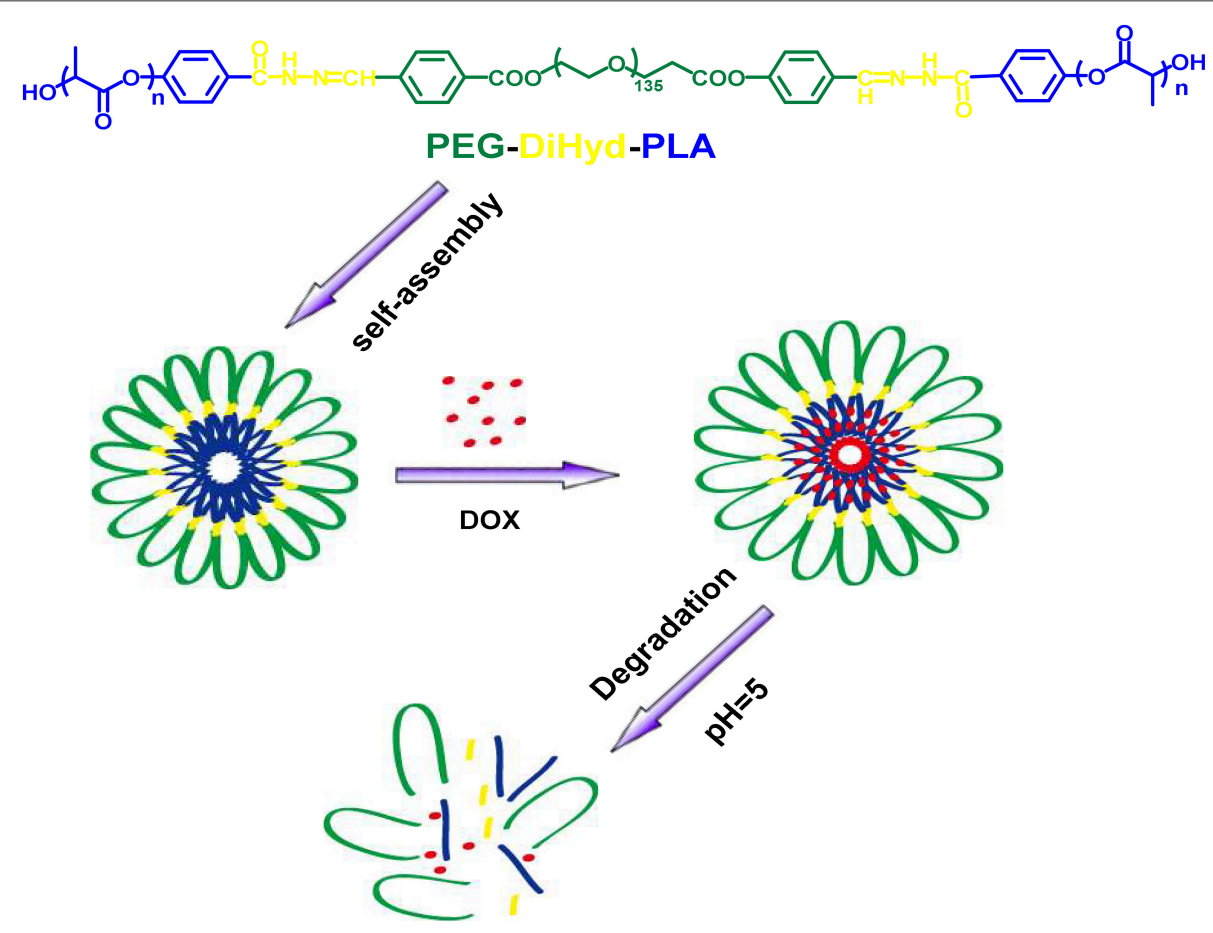

FIGURE 1 | Schematic illustration of the formation of ABA triblock polymer micelle and its degradation in acidic condition. 


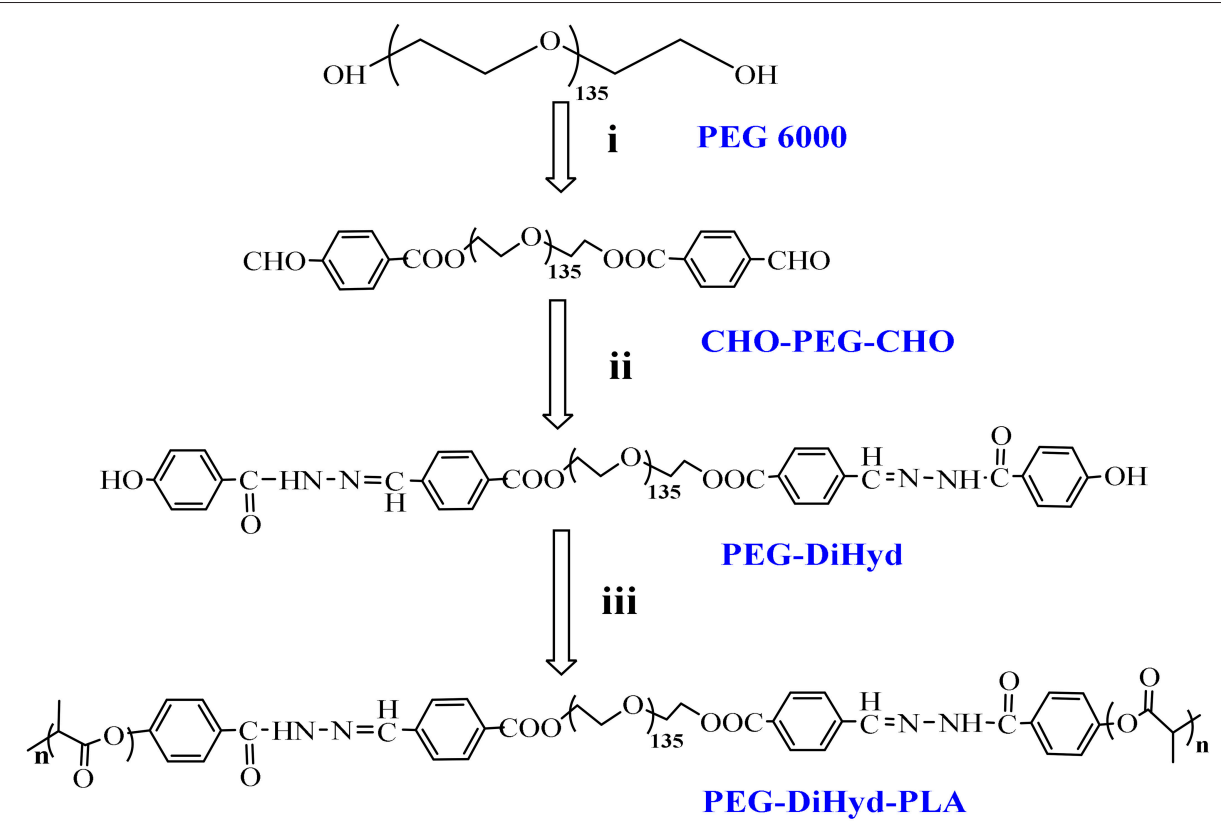

FIGURE 2 | Synthesis route of copolymers PEG-DiHyd-PLA. (i) 4-Formylbenzoic acid, DCC, DMAP,R.T.; (ii) (4-Hydroxybenzoyl) hydrazine, Methanol, DMF, 68 C; (iii) Lactide, $\mathrm{Sn}(\mathrm{oct})_{2}$, Toluene, $110^{\circ} \mathrm{C}, \mathrm{N}_{2}$.

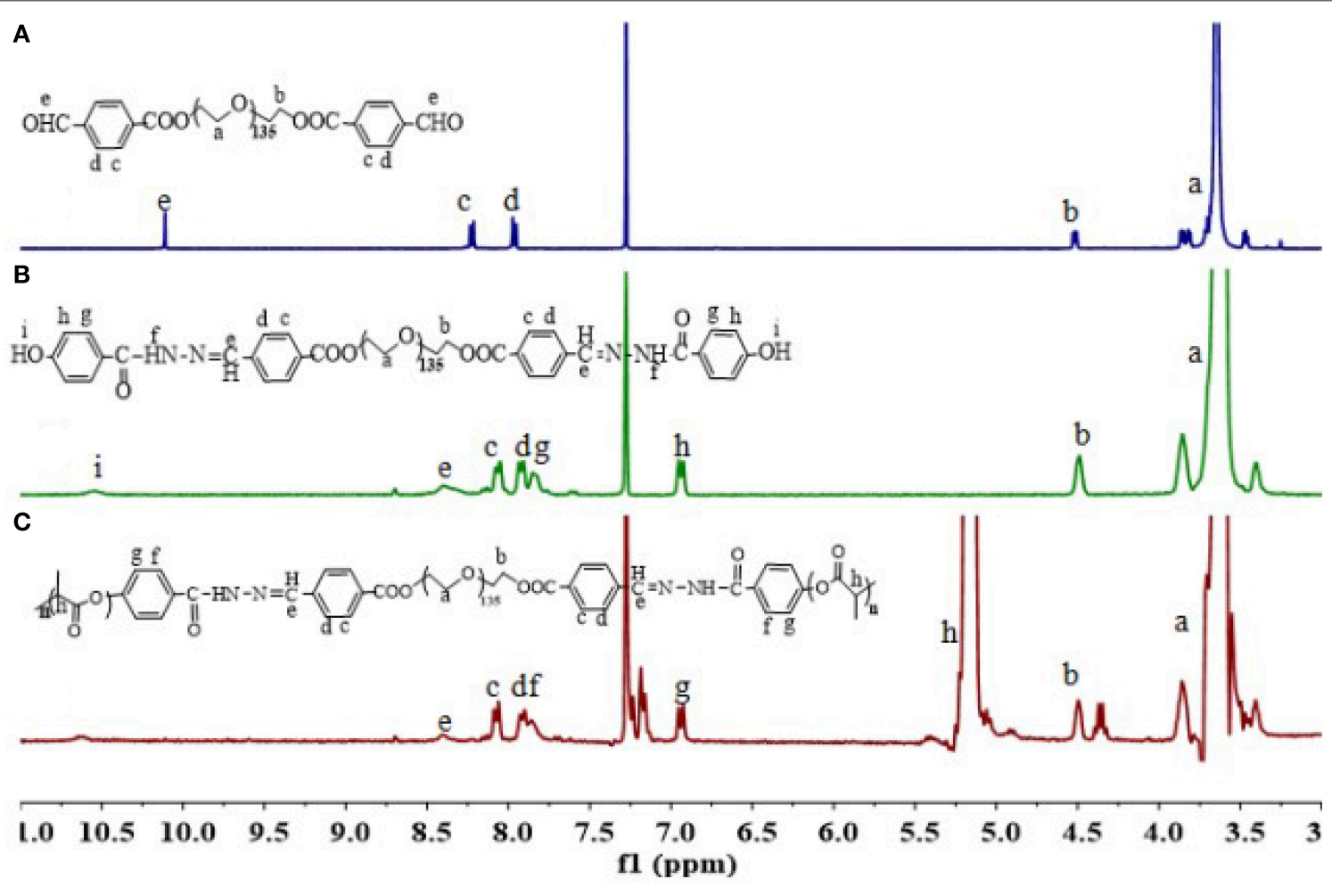

FIGURE 3 $\mid{ }^{1} \mathrm{H}-\mathrm{NMR}$ spectra of polymers CHO-PEG-CHO (A), PEG-DiHyd (B), and PEG-DiHyd-PLA (C).

calculated using the integral ratio between resonances at $\delta 5.16$ (one of methylidyne protons on PLA) and 83.64 (methoxy proton of PEG) in ${ }^{1} \mathrm{H}$-NMR spectra. The calculated values based on ${ }^{1} \mathrm{H}-\mathrm{NMR}$ spectra were consistent with the designed ones. Gel permeation chromatography (GPC) measurements confirmed a unimodal distribution of $\mathrm{Mn}(16.3,18.1$, and 19.7 
$\mathrm{kg} / \mathrm{mol}$, respectively) and narrow distribution [polydispersity index (PDI): 1.31, 1.71, and 1.44]. Therefore, well-defined biodegradable triblock polymers PEG-DiHyd-PLA was successfully synthesized.

Micelles were formed by adding the amphiphilic polymers PEG-DiHyd-PLA into aqueous solution. The micelles have diameters ranged from 70 to $130 \mathrm{~nm}$ and increase with their molecular weight. The average particle size of the drug loaded micelles was larger than that of the blank micelles, which may be due to the larger volume of micelles after the hydrophobic core of the drug loaded with the micelles (Guo et al., 2012; Bao et al., 2014). The loading capacity of DOX loaded polymer PEGDiHyd-PLA-18K micelles was about $4.3 \%$, and the PLA-PEGPLA was $2.7 \%$. As shown in Table 1, the CMC of the polymeric micelles were 1.6, 0.87, and $0.53 \mathrm{mg} / \mathrm{L}$ for PEG-DiHyd-PLA-15K, PEG-DiHyd-PLA-18K, and PEG-DiHyd-PLA-20K, respectively, determined by fluorescence measurements using pyrene as a probe. CMC-values of the polymers decreased from PEG-DiHydPLA-15K to PEG-DiHyd-PLA-20K, which originated from the increased hydrophobic interaction of micelle core. Such a low value of CMC indicates an excellent stability under diluted conditions in vivo, which is so important for the micellar drug delivery system.

The polymer PEG-DiHyd-PLA-18K micelles observed by TEM have a spherical core-shell like structure and are uniformly

TABLE 1 | Synthesis of triblock polymers PEG-DiHyd-PLA.

\begin{tabular}{lcccccc}
\hline Polymer & $\mathbf{( M i / M m}^{\mathbf{a}}$ & $\begin{array}{c}\text { Yield } \\
\mathbf{( \% )}\end{array}$ & $\begin{array}{c}\mathbf{M n}^{\mathbf{b}} \\
\mathbf{( k g / m o l})\end{array}$ & $\begin{array}{c}\mathbf{M n}^{\mathbf{c}} \\
\mathbf{( k g / m o l})\end{array}$ & $\mathbf{P D I}^{\mathbf{d}}$ & $\begin{array}{c}\mathbf{C M C}^{\mathbf{e}} \\
\mathbf{( m g} / \mathbf{L})\end{array}$ \\
\hline PEG-DiHyd-PLA-15k & $1: 127$ & 72 & 15.9 & 16.3 & 1.31 & 1.6 \\
PEG-DiHyd-PLA-18k & $1: 169$ & 82 & 19.3 & 18.1 & 1.71 & 0.87 \\
PEG-DiHyd-PLA-20k & $1: 197$ & 69 & 21.8 & 19.7 & 1.44 & 0.53 \\
\hline
\end{tabular}

${ }^{a}$ Feed ratios in mole between initiator and monomer.

${ }^{b}$ Calculated from ${ }^{1} \mathrm{H}$-NMR spectra.

${ }^{c} \mathrm{GPC}$ results.

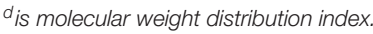

${ }^{e}$ Critical micelle concentration determined using pyrene as a fluorescent probe. distributed (Figure 4a), the particle size of the polymer PEGDiHyd-PLA-18K micelles measured by DLS is relatively small, both of which are about $70 \mathrm{~nm}$, and the particle size distribution is narrow and PDI is lower than 0.2 (Figure $4 \mathbf{b}$ ). It shows that the size of micelles is relatively uniform, and the particle

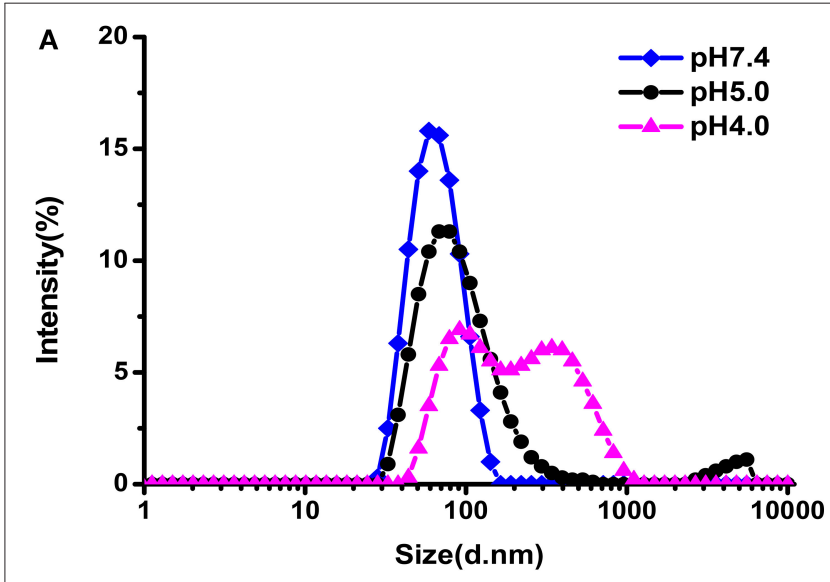

B

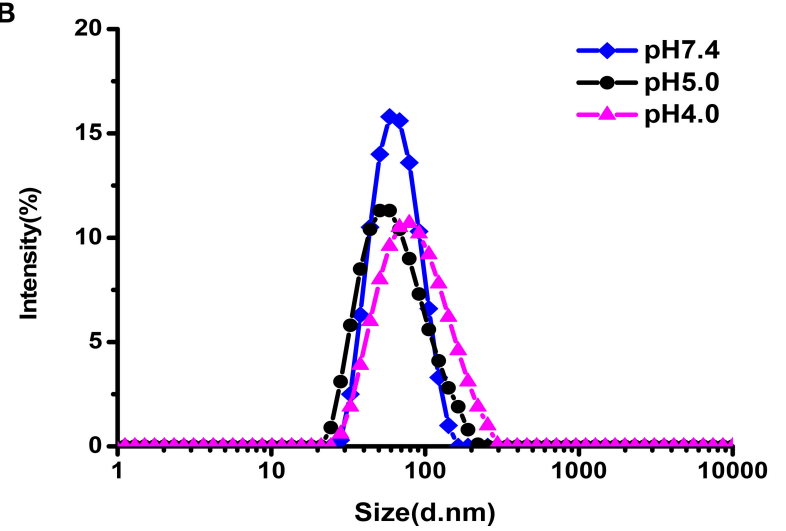

FIGURE 5 | The size change of PEG-DiHyd-PLA-18K (A); PLA-PEG-PLA-18K (B) micelles at different $\mathrm{pH}$ for $24 \mathrm{~h}$.
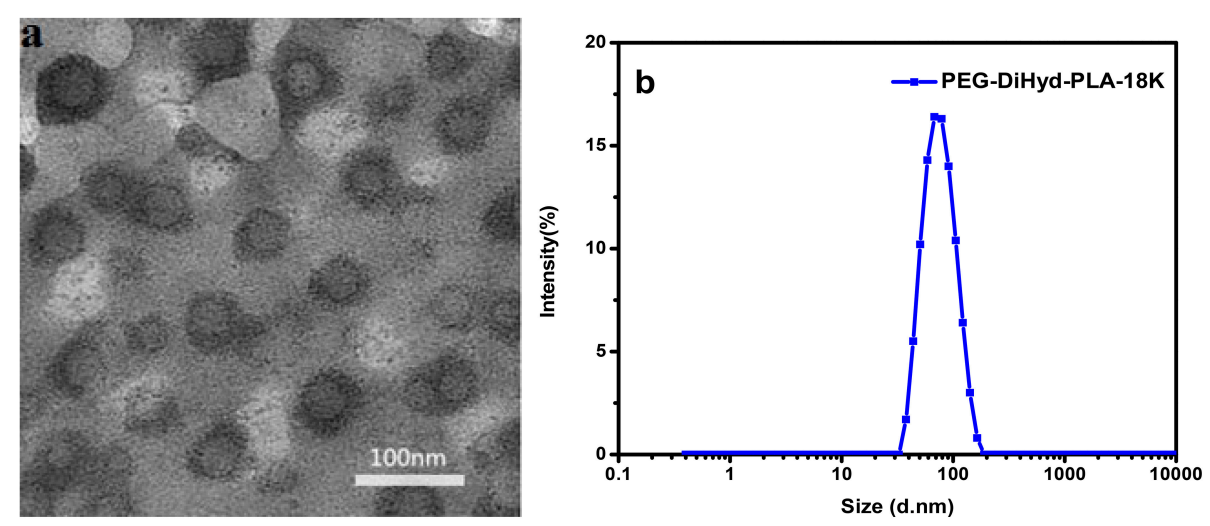

FIGURE 4 | Images of micelles formed by PEG-DiHz-PLA-18K (a). The particle size of PEG-DiHyd-PLA-18K micelles (b). 
size of micelle is basically consistent with the result of TEM determination. It was reported that nanoparticulate drug carriers can accumulate in tumor tissue via the enhanced permeability and retention (EPR) effect (Baish et al., 2011; Maeda and Matsumura, 2011) when their sizes are $<200 \mathrm{~nm}$. Thus, PEGDiHyd-PLA micelles would effectively reach lesion sites, and achieve the goal of $\mathrm{pH}$-controlled drug delivery.

\section{pH-Triggered Size Change of the Blank Micelles}

The $\mathrm{pH}$-responsive evolution of micelle was monitored by DLS measurements. As illustrated in Figure 5A, the size distribution of hydrazone-containing PEG-DiHyd-PLA-18K micelles underwent obvious changes under acidic conditions $(\mathrm{pH}$ 4.0, $\mathrm{pH}$ 5.0) while stable under physiological condition ( $\mathrm{pH}$ 7.4). Multiple peaks appeared in the DLS curve and the solution became turbid due to precipitation, which was resulted from the decomposition of the $\mathrm{pH}$-sensitive micelles in acidic environments. In contrast, PLA-PEG-PLA-18K micelles without hydrazone bonds kept almost unchanged under all $\mathrm{pH}$ conditions
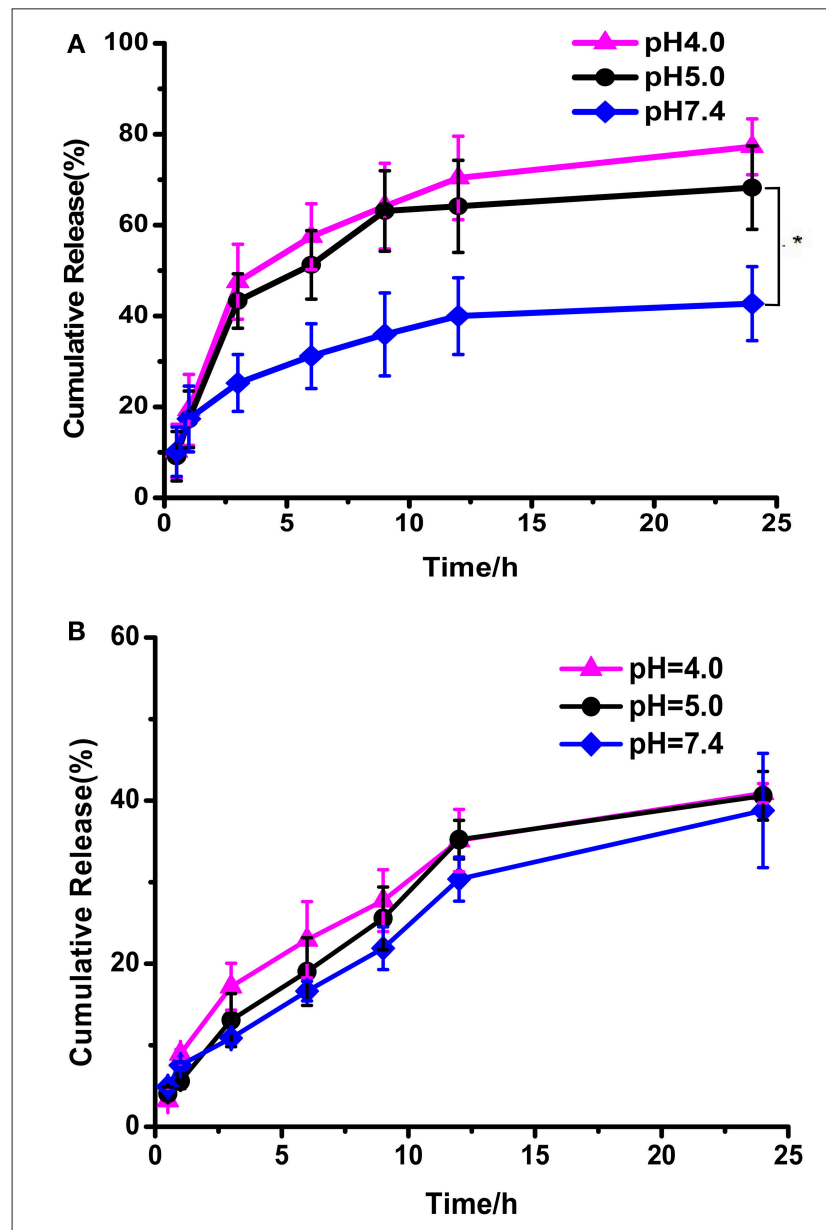

FIGURE 6 | In vitro release of DOX from PEG-DiHZ-PLA-18K (A); PLA-PEG-PLA-18K (B) micelles. Error bars indicate the standard error of the mean (SEM) for $n=3$ independent experiments $\left({ }^{*} p<0.05\right)$.
(Figure 5B) in $24 \mathrm{~h}$. It is supported that the $\mathrm{pH}$ sensitive micelles will keep stable in blood circulation and protect their payload from being released before access targeting tumor tissue. After they encounter tumor tissue via EPR effector internalized by tumor cell where there is acidic condition, the loaded drug will be released instantly.

\section{In Vitro Controlled Release of DOX}

The in vitro drug release behaviors under various conditions were investigated (Figure 6A). DOX released from DOX loaded PEG-DiHyd-PLA-18K micelles at physiological $\mathrm{pH}$ was about ca. $38 \%$ in $24 \mathrm{~h}$. The release rate was significantly promoted at $\mathrm{pH} 5.0$ and 4.0, with accumulated release above $75 \%$ in $24 \mathrm{~h}$, and there is no obvious difference between them. It is the $\mathrm{pH}$-sensitive hydrazone bond results the $\mathrm{pH}$-controlled drug release profile of polymeric PEG-DiHyd-PLA-18K micelles. Comparably, Figure 6B, the release of DOX from $\mathrm{pH}$ insensitive polymeric micelles showed a similar rate of release. Under different $\mathrm{pH}$ conditions, there was no $\mathrm{pH}$-dependent release profile, with cumulative release of about $40 \%$ in $24 \mathrm{~h}$. This results are consistent with the size changes in different conditions for the two types of micelles. The $\mathrm{pH}$-responsive release of the hydrazone containing micelles might underwent a cleavage-disassociationrelease process.

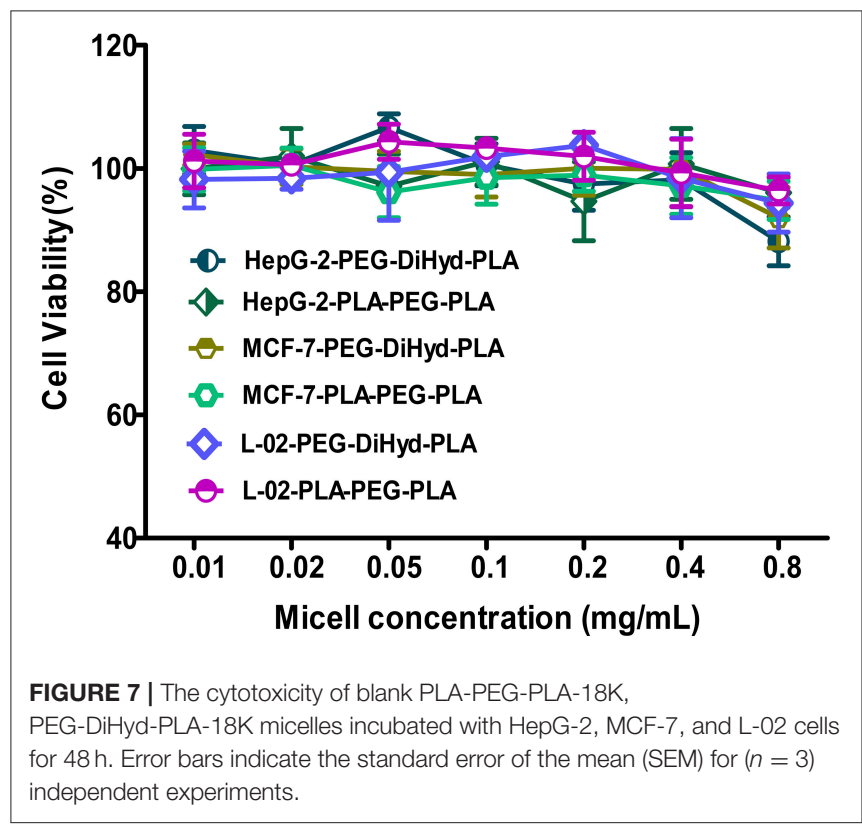

TABLE 2 | Half-inhibitory concentration $\left(\mathrm{IC}_{50}\right)$ of loaded-DOX micelles and free DOX on HepG-2, MCF-7, and L-02 cells.

\begin{tabular}{lccc}
\hline $\mathbf{I C}_{\mathbf{5 0}}(\boldsymbol{\mu} \mathbf{g} / \mathbf{m L})$ & $\begin{array}{c}\text { HepG-2 } \\
\mathbf{4 8} \mathbf{~ h}\end{array}$ & $\begin{array}{c}\text { MCF-7 } \\
\mathbf{4 8 ~} \mathbf{~}\end{array}$ & $\begin{array}{c}\mathbf{L - 0 2} \\
\mathbf{4 8} \mathbf{~}\end{array}$ \\
\hline PLA-PEG-PLA-DOX & 4.601 & 4.053 & 6.464 \\
PEG-DiHyd-PLA-DOX & 3.098 & 2.303 & 7.178 \\
Free DOX & 2.182 & 1.615 & 1.486
\end{tabular}




\section{MTT Assay of DOX-Loaded Micelles}

The cytotoxicity of the blank micelles were tested in MCF-7, HepG-2, and normal hepatocyte L-02 cells by a MTT assay. Cells viabilities of cells was above $90 \%$ for both blank PLA-PEGPLA-18K and PEG-DiHyd-PLA-18K micelles following $48 \mathrm{~h}$ incubation (Figure 7), which meant that the blank micelles are remarkably no-toxic and biocompatible up to a concentration of $0.8 \mathrm{mg} / \mathrm{mL}$.

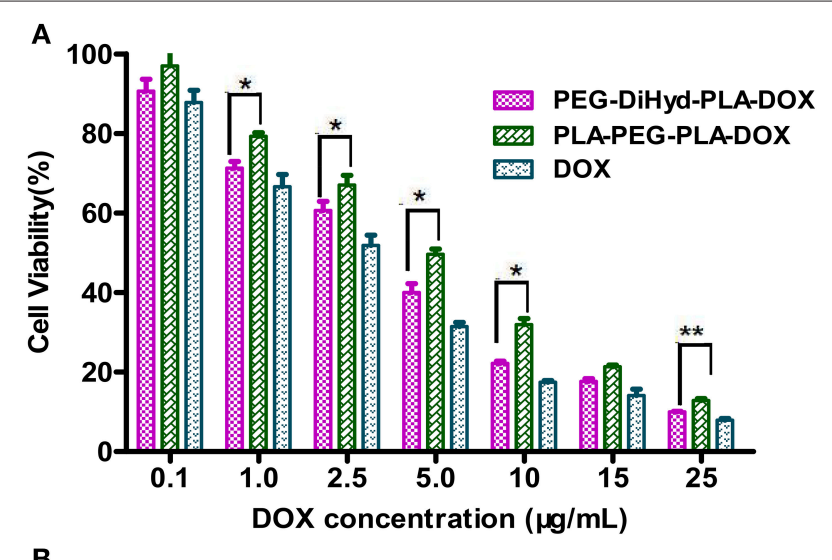

B

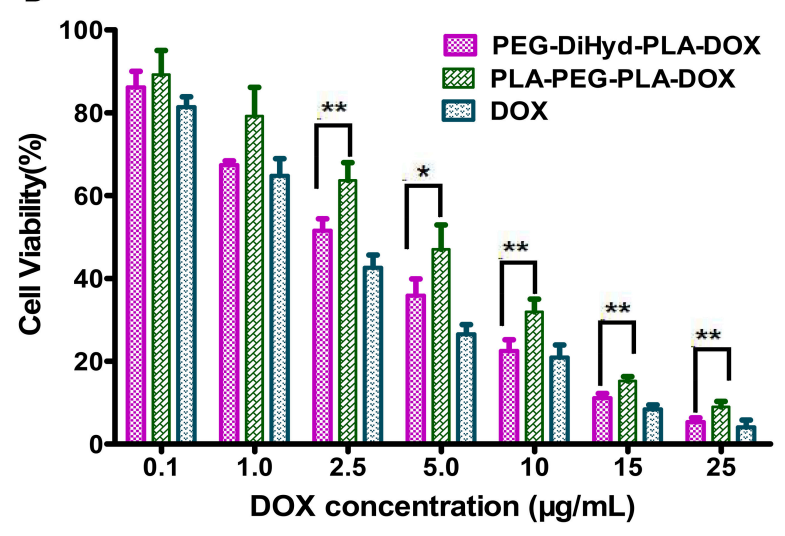

C

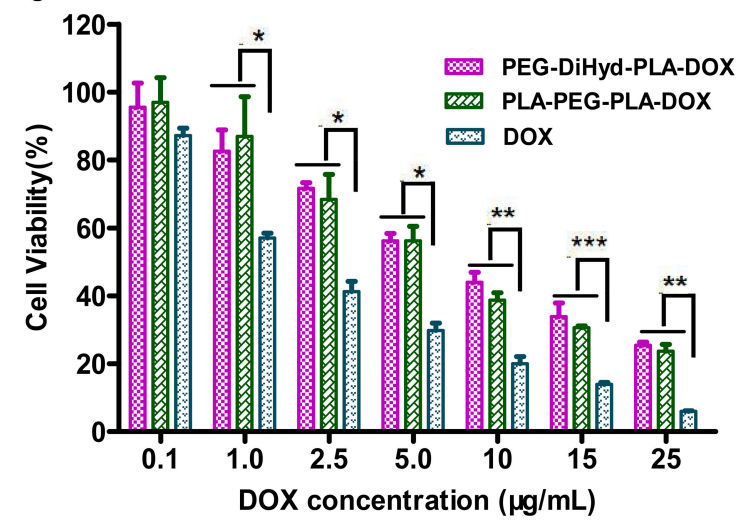

FIGURE 8 | The cytotoxicity of DOX loaded PLA-PEG-PLA-18K,

PEG-DiHyd-PLA-18K micelles and Free DOX incubated with HepG-2 cells (A), MCF-7 cells (B), and L-02 (C) at different DOX concentrations $48 \mathrm{~h}$. Data were presented as mean \pm standard deviation $(n=3)\left({ }^{\star} p<0.05,{ }^{* \star} p<0.01,{ }^{* \star *} p<\right.$ 0.001).
In vitro antitumor capability of PEG-DiHyd-PLA-18K based drug delivery systems are tested. Formulations including free DOX, DOX loaded PLA-PEG-PLA-18K, and PEG-DiHyd-PLA$18 \mathrm{~K}$ micelles were evaluated against MCF-7, HepG-2, and L-02 cell lines. The $\mathrm{IC}_{50}$-values for various $\mathrm{DOX}$ for mutations and free DOX are summarized in Table 2, As shown in Figure 8, for

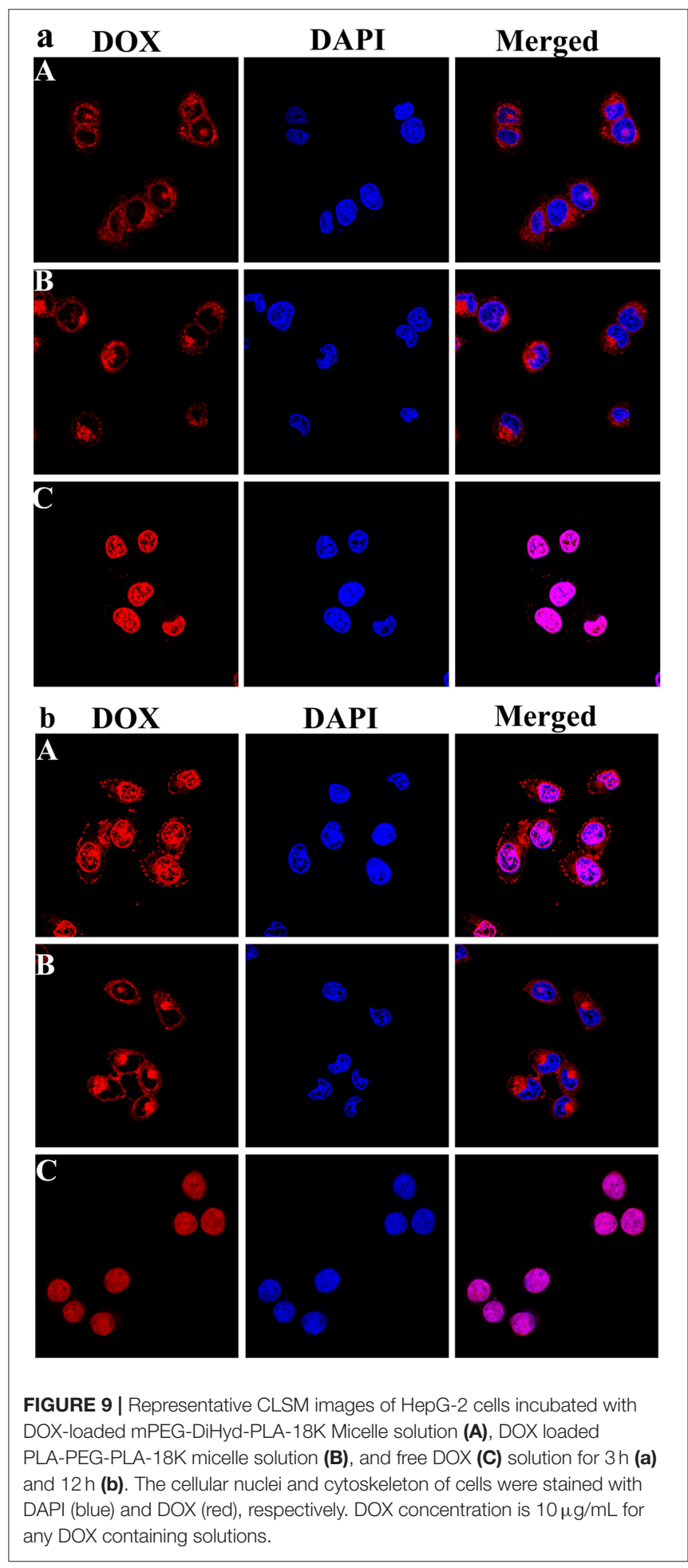




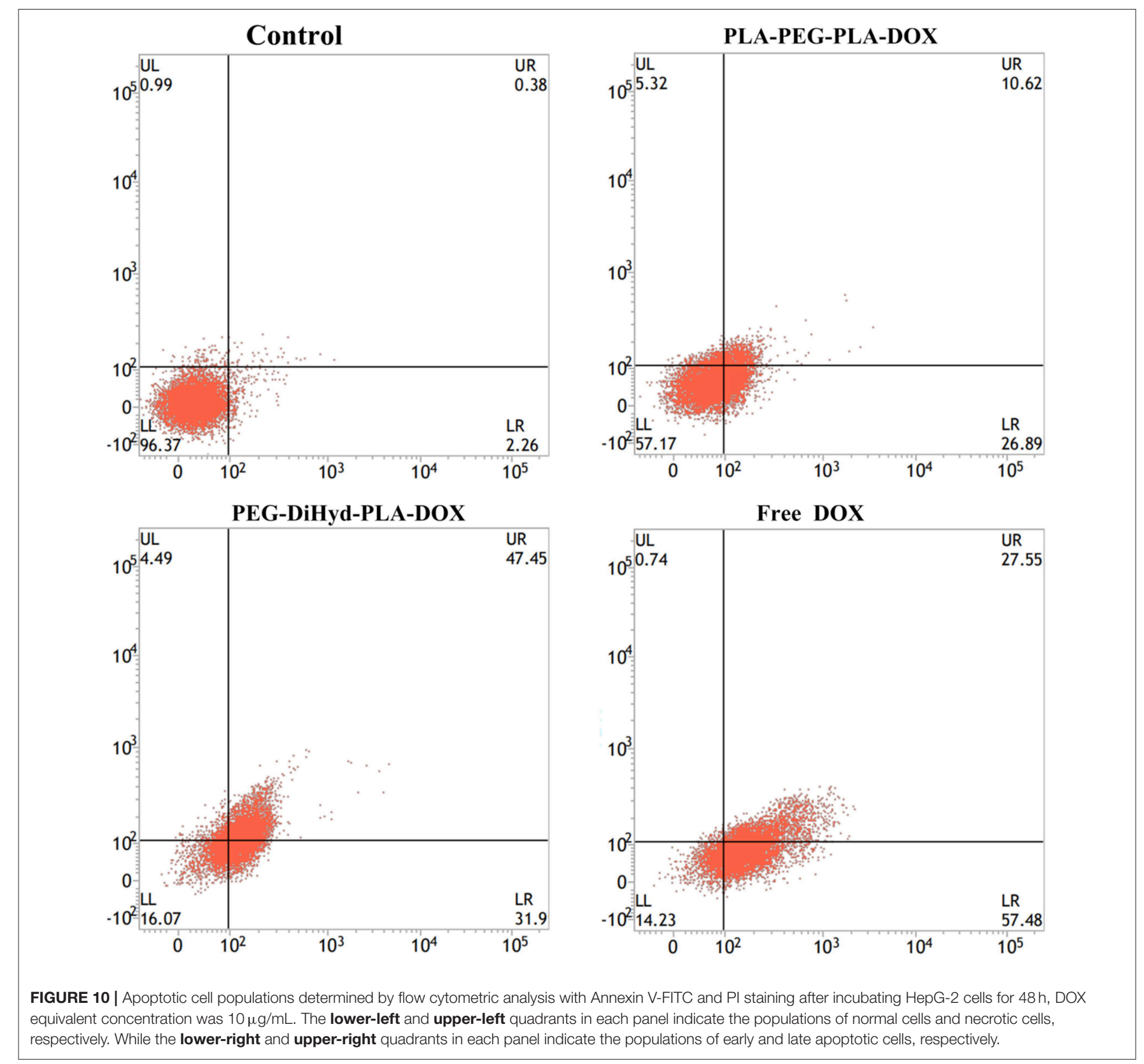

all of the cells, the formulations showed a dose dependent cell proliferation inhibition behaviors after a $48 \mathrm{~h}$ incubation, free DOX showed higher in vitro toxicity to each cell, compared to the other two micelle formulations. DOX is a small molecule, so it can be quickly transported into cells and reach nuclei by passive diffusion (Cui et al., 2013). This is why the inhibition effect of free DOX was the strongest. While, for HepG-2 and MCF-7 cells (Figures 8A,B), pH sensitive DOX loaded PEGDiHyd-PLA-18K micelles was more toxic than DOX loaded PLAPEG-PLA-18K. Superior cell-killing capability of DOX loaded PEG-DiHyd-PLA-18K micelles may be due to the fact that entry of $\mathrm{pH}$-sensitive micelles through endocytosis and drug release into the cytoplasm triggered by endosome $\mathrm{pH}$ are quick and efficient processes (Tang et al., 2011). As shown in Figure 8C, compared with free DOX, the DOX-loaded micelles exhibited significantly reduced cytotoxicity on L- 02 cells, which is probably due to their slower uptake of DOX-loaded micelles by L-02 cells. While, there was no significant difference in the cytotoxicity between the two DOX-loaded micelles, which could be attributed to the limited of acid environment in L-02 cells compared with tumor cells (Qin et al., 2017).

\section{Cellular Uptake of the Drug-Loaded Micelles}

The intracellular localization and distribution of DOX-loaded micelles were investigated in HepG-2 cells using CLSM after 
incubation for 3 and 12 h (Figure 9). As shown in Figure 9a, for the DOX loaded micelles, most of the red fluorescence appears in the cytoplasm, and there is no obvious difference between the two drug loaded micelles. But with extended incubation time to $12 \mathrm{~h}$, it was also observed that the $\mathrm{pH}$ sensitive DOXloaded PEG-DiHyd-PLA-18K micelles showed relatively strong red fluorescence in the nucleus, while the red fluorescence of the DOX-loaded PLA-PEG-PLA-18K micelles was mainly in the cytoplasm and the nuclei were less (Figure 9b). That was due to the accelerated DOX release from hydrazone-containing micelles in the acidic tumor microenvironment. The accumulation of DOX-loaded micelles was lower than that of free DOX with the same incubation time, the possible reason is that free DOX transported into cells via a passive diffusion mechanism (Li et al., 2014). Compared to DOX-loaded PLA-PEG-PLA$18 \mathrm{~K}$ micelles, the quick and efficient uptake of DOX from $\mathrm{pH}$ sensitive micelles greatly inhibited the growth of the tumor cell.

\section{Apoptosis of the Drug-Loaded Micelles}

Apoptosis has been reported to be one of the primary mechanisms of action of DOX (Wang et al., 2017). Incubated with HepG-2 cells at a equivalent concentration of $10 \mu \mathrm{g} / \mathrm{mL}$ DOX for $48 \mathrm{~h}$ (Yang et al., 2016), the effect of free DOX, DOX loaded PLA-PEG-PLA-18K, and PEG-DiHyd-PLA-18K micelles on apoptosis was shown in Figure 10, the total apoptosis ratio of DOX-loaded PLA-PEG-PLA-18K micelles was about 38\% (a sum of the early apoptosis ratio of $26.89 \%$ and the late apoptosis ratio of $10.62 \%)$. With the HepG-2 cells treated with $\mathrm{pH}$ sensitive DOX loaded PEG-DiHyd-PLA-18K micelles, there is a $78 \%$ apoptosis ratio which is higher than $38 \%$, which is likely due to the e accelerated release of the drug molecules from micelles with acidlabile hydrazone linkage by sensing the acidic environment of the endosomal compartments. The higher apoptosis rate of free DOX with the same incubation time, most likely because free DOX could diffuse passively through cell membranes quicker, whereas drug loaded micelles were internalized into cells via slower endocytosis (Hu et al., 2010). Apoptosis experiment again

\section{REFERENCES}

Ahmad, Z., Tang, Z. H., Shah, A., Lv, S. X., Zhang, D. W., Zhang, Y., et al. (2014). Cisplatin loaded methoxy poly (ethylene glycol)-block-poly (L-glutamic acidco-L-phenylalanine) nanoparticles against human breast cancer cell. Macromol. Biosci. 14, 1337-1345. doi: 10.1002/mabi.201400109

Bae, Y., Fukushima, S., Harada, A., and Kataoka, K. (2003). Design of environmentsensitive supramolecular assemblies for intracellular drug delivery: polymeric micelles that are responsive to intracellular $\mathrm{pH}$ change. Angew. Chem. Int. Edn. 42, 4640-4643. doi: 10.1002/anie.200250653

Baish, J. W., Stylianopoulos, T., Lanning, R. M., Kamoun, W. S., Fukumura, D., Munn, L. L., et al. (2011). Scaling rules for diffusive drug delivery in tumor and normal tissues. Proc. Natl. Acad. Sci. U.S.A. 108, 1799-1803. doi: 10.1073/pnas.1018154108

Bao, Y., Guo, Y., Zhuang, X., Cheng, B., Tan, S., and Zhang, Z. (2014). D-tocopherol polyethylene glycol succinate-based redox-sensitive paclitaxel prodrug for overcoming multidrug resistance in cancer cells. Mol. Pharm. 11, 3196-3209. doi: 10.1021/mp500384d confirms the superiority advantages of $\mathrm{pH}$ sensitive micelles in tumor targeting therapy.

\section{CONCLUSIONS}

In this work, a type of $\mathrm{pH}$-sensitive polymeric micelles was prepared as carrier of DOX. A triblock copolymer has one hydrophilic PEG segment and two hydrophobic PLA segments. $\mathrm{pH}$-sensitive hydrazone bond was used to connect them together, denoted as PEG-DiHyd-PLA. The copolymercan self-assemble into micelles with uniformed size below $100 \mathrm{~nm}$ and narrow size distribution. The size of the hydrazone-containing micelles underwent obviously changes in mildy acidic environments while kept unchanged in the neutral. Almost no change was found for polymeric micelles without hydrazone (PLA-PEG-PLA). DOX was successfully loaded into the micelles and presented a more rapid and complete drug release in acidic condition ( $\mathrm{pH}$ 5.0). The results of in vitro cell assay revealed that the blank micelles were non-toxic and good biocompatibility. DOX-loaded PEGDiHyd-PLA micelles possessed higher anti-tumor activity to kill the MCF-7 and HepG-2 cells in comparison with DOX loaded PLA-PEG-PLA micelles and less cytotoxicity to normal L-02 cells at similar DOX concentrations. Confocal and apoptotic experiments also proved that superiority advantages of $\mathrm{pH}$ sensitive micelles for tumor therapy.

\section{AUTHOR CONTRIBUTIONS}

$\mathrm{PQ}$, performed the synthesis and characterizations; XW, performed the cell experiments; LL, designed the synthesis and wrote the paper; HY, performed the formulations; SS, designed the whole experiment.

\section{ACKNOWLEDGMENTS}

Thanks to the supported of the National Natural Science Foundation of China (NSFC 51375142) and a key project funded by the Education Department of Henan Province (13A360054).

Cao, J., Su, T., Zhang, L., Liu, R., Wang, G., He, B., et al. (2014). Polymeric micelles with citraconic amide as $\mathrm{pH}$-sensitive bond in backbone for anticancer drug delivery. Int. J. Pharm. 471, 28-36. doi: 10.1016/j.ijpharm.2014. 05.010

Cavallaro, G., Licciardi, M., Amato, G., Sardo, C., Giammona, G., Farra, R., et al. (2014). Synthesis and characterization of polyaspartamide copolymers obtained by ATRP for nucleic acid delivery. Int. J. Pharm. 466, 246-257. doi: 10.1016/j.ijpharm.2014.03.026

Cheng, J., Ji, R., Gao, S. J., Du, F. S., and Li, Z. C. (2012). Facile synthesis of acid-labile polymers with pendent ortho esters. Biomacromolecules 13, 173-179. doi: 10.1021/bm201410c

Cheng, R., Meng, F. H., Deng, C., and Zhong, Z. Y. (2015). Bioresponsive polymeric nanotherapeutics for targeted cancer chemotherapy. Nano Today 10, 656-670. doi: 10.1016/j.nantod.2015.09.005

Cui, C., Xue, Y. N., Wu, M., Zhang, Y., Yu, P., Liu, L., et al. (2013). Cellular uptake, intracellular trafficking, and antitumor efficacy of doxorubicin-loaded reduction-sensitive micelles. Biomaterials 34, 3858-3869. doi: 10.1016/j.biomaterials.2013.01.101 
Deng, B., Ma, P., and Xie, Y. (2015). Reduction-sensitive polymeric nanocarriers in cancer therapy: a comprehensive review. Nanoscale 7, 12773-12795. doi: 10.1039/C5NR02878G

Ding, C., Gu, J., Qu, X., and Yang, Z. (2009). Preparation of multifunctional drug carrier for tumor-specific uptake and enhanced intracellular delivery through the conjugation of weak acid labile linker. Bioconjug. Chem. 20, 1163-1170. doi: $10.1021 / \mathrm{bc} 800563 \mathrm{~g}$

Gillies, E. R., Goodwin, A. P., and Fréchet, J. M. (2004). Acetals as pHsensitive linkages for drug delivery. Bioconjug. Chem. 15, 1254-1263. doi: 10.1021/bc049853x

Guo, Y., Wang, X., Shu, X., Shen, Z., and Sun, R. C. (2012). Self-assembly and paclitaxel loading capacity of cellulose-graft-poly(lactide) nanomicelles. $J$. Agric. Food Chem. 60, 3900-3908. doi: 10.1021/jf3001873

Han, Y. N., Liu, S. X., Mao, H. G., Tian, L., and Ning, W. Y. (2016). Studies on the synthesis, micellization and gelation of novel temperature and pH-sensitive ABA triblock copolymers. Acta Chim. Sinica 74, 744-751. doi: 10.6023/A16060302

Hrubý, M., Konák, C., and Ulbrich, K. (2005). Polymeric micellar pH-sensitive drug delivery system for doxorubicin. J. Control. Release 103, 137-148. doi: 10.1016/j.jconrel.2004.11.017

Hu, X., Liu, S., Huang, Y., Chen, X., and Jing, X. (2010). Biodegradable block copolymer-doxorubicin conjugates via different linkages: preparation, characterization, and in vitro evaluation. Biomacromolecules 11, 2094-2102. doi: $10.1021 / \mathrm{bm} 100458 \mathrm{n}$

Huang, F., Cheng, R., Meng, F., Deng, C., and Zhong, Z. (2015). Micelles based on acid degradable poly(acetal urethane): preparation, $\mathrm{pH}$-sensitivity, and triggered intracellular drug release. Biomacromolecules 16, 2228-2236. doi: 10.1021/acs.biomac.5b00625

Li, N., Li, N., Yi, Q. Y., Luo, K., Guo, C. H., Pan, D., et al. (2014). Amphiphilic peptide dendritic copolymer-doxorubicin nanoscale conjugate self-assembled to enzyme-responsive anti-cancer agent. Biomaterials 35, 9529-9545. doi: 10.1016/j.biomaterials.2014.07.059

Lu, J. S., Li, N. J., Xu, Q. F., Ge, J. F., Lu, J. M., and Xia, X. W. (2010). Acetals moiety contained $\mathrm{pH}$-sensitive amphiphilic copolymer self-assembly used for drug carrier. Polymer 51, 1709-1715. doi: 10.1016/j.polymer.2009.12.034

Maeda, H., and Matsumura, Y. (2011). EPR effect based drug design and clinical outlook for enhanced cancer chemotherapy. Adv. Drug Delivery Rev. 63, 129-130. doi: 10.1016/j.addr.2010.05.001

Makino, J., Cabral, H., Miura, Y., Matsumoto, Y., Wang, M., Kinoh, H., et al. (2015). cRGD-installed polymeric micelles loading platinum anticancer drugs enable cooperative treatment against lymph node metastasis. J. Control. Release 220, 783-791. doi: 10.1016/j.jconrel.2015.10.017

McPherson, T., Szleifer, I., Park, K., and Kidane, A. (1998). Prevention of protein adsorption by tethered poly(ethylene oxide) layers: experiments and singlechain mean-field analysis. Langmuir 14, 176-186. doi: 10.1021/la9706781

Mei, L., Liu, Y. Y., Zhang, H. J., Zhang, Z. R., and Gao, H. L. (2016). Antitumor and antimetastasis activities of heparin-based micelle served as both carrier and drug. ACS Appl. Mater. Inter. 8, 9577-9589. doi: 10.1021/acsami.5b12347

Park, K. C., Idota, N., and Tsukahara, T. (2014). Synthesis of NIPAAm-based polymer-grafted silica beads by surface-initiated ATRP using Me 4 cyclam ligands and the thermo-responsive behaviors for lanthanide(III) ions. React. Funct. Polym. 79, 36-46. doi: 10.1016/j.reactfunctpolym.2014.03.011

Qi, P. L., Bu, Y. Q., Xu, J., Qin, B. K., Luan, S. J., and Song, S. Y. (2017). $\mathrm{pH}$-responsive release of paclitaxel from hydrazone-containing biodegradable micelles. Colloid Polym. Sci. 295, 1-12. doi: 10.1007/s00396-016-3968-6

Qin, B. K., Liu, L., Wu, X., Liang, F., Hou, T., Pan, Y., et al. (2017). mPEGylated solanesol micelles as redox-responsive nanocarriers with synergistic anticancer effect. Acta Biomater. 64, 211-222. doi: 10.1016/j.actbio.2017.09.040

Ran, J., Wu, L., Zhang, Z. H., and Xu, T. W. (2014). Atom transfer radical polymerization (ATRP): a versatile and forceful tool for functional membranes. Prog. Polym. Sci. 39, 124-144. doi: 10.1016/j.progpolymsci.2013.09.001
Seo, B. B., Choi, H., Koh, J. T., and Song, S. C. (2015). Sustained BMP-2 delivery and injectable bone regeneration using thermosensitive polymeric nanoparticle hydrogel bearing dual interactions with BMP-2. J. Control. Release 209, 67-76. doi: 10.1016/j.jconrel.2015.04.023

Sinha, V. R., Bansal, K. R., Kumria, R., and Trehan, A. (2004). Poly-epsiloncaprolactone microspheres and nanospheres: an overview. Int. J. Pharm. 278, 1-23. doi: 10.1016/j.ijpharm.2004.01.044

Tang, R., Ji, W., Panus, D., Palumbo, R. N., and Wang, C. (2011). Block copolymer micelles with acid-labile ortho ester side-chains: synthesis, characterization, and enhanced drug delivery to human glioma cells. J. Control. Release 151, 18-27. doi: 10.1016/j.jconrel.2010.12.005

Ulbrich, K., and Šubr, V. (2010). Structural and chemical aspects of HPMA copolymers as drug carriers. Adv. Drug Deliv. Rev. 62, 150-166. doi: 10.1016/j.addr.2009.10.007

Visnevskij, C., Ciuta, G., Ketleriute, S., Savickaite, M., and Makuska, R. (2014). ISARA ATRP of methacrylic acid neutralized by simple amines yielding linear polymers and anionic molecular brushes. R. Eur. Polym. J. 55, 66-75. doi: 10.1016/j.eurpolymj.2014.03.031

Vonarbourg, A., Passirani, C., Saulnier, P., and Benoit, J. P. (2006). Parameters influencing the stealthiness of colloidal drug delivery systems. Biomaterials 27, 4356-4373. doi: 10.1016/j.biomaterials.2006.03.039

Wang, Y. D., Chen, J. W., Liang, X., Han, H. B., Wang, H., and Li, Q. S. (2017). An ATP-responsive codelivery system of doxorubicin and MiR-34a to synergistically inhibit cell proliferation and migration. Mol. Pharm. 14, 2323-2332. doi: 10.1021/acs.molpharmaceut.7b00184

Webb, B. A., Chimenti, M., Jacobson, M. P., and Barber, D. L. (2011). Dysregulated pH: a perfect storm for cancer progression. Nat. Rev. Cancer 11, 671-677. doi: $10.1038 / \operatorname{nrc} 3110$

Witschi, C., and Doelker, E. (1998). Influence of the microencapsulation method and peptide loading on poly(lactic acid) and poly(lactic-co-glycolic acid) degradation during in vitro testing. J. Control. Release 51, 327-341. doi: 10.1016/S0168-3659(97)00188-0

Xing, L., Zheng, H. Q., and Che, S. A. (2011). A pH-responsive cleavage route based on a metal-organic coordination bond. Chem. Eur. J. 17, 7271-7275. doi: 10.1002/chem.201003005

Xu, J., Luan, S. J., Qin, B. K., Wang, Y. Y., Wang, K., and Qi, P. L. (2016). Backbonehydrazone-containing biodegradable copolymeric micelles for anticancer drug delivery. J. Nanopart. Res. 18, 316-331. doi: 10.1007/s11051-016-3626-4

Yang, J., Wu, Y. P., Shen, Y., Zhou, C. G., Li, Y. F., and He, R. R. (2016) Enhanced therapeutic efficacy of doxorubicin for breast cancer using chitosan oligosaccharide-modified halloysite nanotubes. ACS Appl. Mater. Inter. 40, 26578-26590. doi: 10.1021/acsami.6b09074

Zheng, H. Q., Xing, L., Cao, Y. Y., and Che, S. A. (2013). Coordination bonding based pH-responsive drug delivery systems. Chem. Rev. 257, 1933-1944. doi: 10.1016/j.ccr.2013.03.007

Zheng, H. T., Hua, D. B., Bai, R. K., Hu, K. L., An, L. J., and Pan, C. Y. (2007). Control led/living free-radical copolymerization of 4-(azidocarbonyl) phenyl methacrylate with methyl acrylate under Co-60 gamma-ray irradiation. J. Polym. Sci. Pol. Chem. 45, 2609-2616. doi: 10.1002/pola. 22018

Conflict of Interest Statement: The authors declare that the research was conducted in the absence of any commercial or financial relationships that could be construed as a potential conflict of interest.

Copyright (c) $2018 \mathrm{Qi}, \mathrm{Wu}, \mathrm{Liu}, \mathrm{Yu}$ and Song. This is an open-access article distributed under the terms of the Creative Commons Attribution License (CC BY). The use, distribution or reproduction in other forums is permitted, provided the original author(s) or licensor are credited and that the original publication in this journal is cited, in accordance with accepted academic practice. No use, distribution or reproduction is permitted which does not comply with these terms. 